\title{
RETRACTED ARTICLE: Biceps tendon interposition in two-part fracture of the humeral surgical neck
}

\author{
Selim Şanel ${ }^{1}$ - Yalçın Turhan ${ }^{2}$ (I) $\cdot$ Nurullah Ermiş $^{1} \cdot$ Korhan Özkan $^{3} \cdot$ Ender Uğutmen ${ }^{1}$
}

Received: 31 October 2017 / Accepted: 17 January 2018 / Published online: 23 January 2018

○) Springer-Verlag France SAS, part of Springer Nature 2018

This article is retracted by the authors because its content has been duplicated from an unpublished manuscript without permission. All authors agree to this retraction. The online version of this article contains the full text of the retracted article as electronic supplementary material.

Electronic supplementary material The online version of this article (https://doi.org/10.1007/s00590-018-2128-8) contains supplementary material, which is available to authorized users.

Yalçın Turhan

yturhan_2000@yahoo.com

Selim Şanel

selim.sanel@maltepe.edu.tr

Nurullah Ermiş

nurullah.ermis@maltepe.edu.tr

Korhan Özkan

korhanozkan76@gmail.com

Ender Uğutmen

ender.ugutmen@maltepe.edu.tr

1 Orthopedics and Traumatology Department, Medical

Faculty, Maltepe University, İstanbul, Turkey

2 Orthopedics and Traumatology Department, Medical Faculty, Duzce University, Duzce, Turkey

3 Orthopedics and Traumatology Department, Medical Faculty, Medeniyet University, Istanbul, Turkey 